\title{
Frailty and mortality among dialysis patients
}

Kosaku Nitta ${ }^{1 *}$, Norio Hanafusa ${ }^{2}$ and Ken Tsuchiya ${ }^{2}$

\begin{abstract}
Frailty is a clinical state in which there is an increase in the individual's vulnerability to developing increased dependency and/or mortality when exposed to a stressor. Since the mean age of dialysis patients is increasing worldwide, frailty has recently come to be considered one of the risk factors for mortality in the older dialysis population. The prevalence of frailty among dialysis patients has ranged from 3.0- to 10-fold higher than that among community-dwelling elderly, depending on the method of assessing frailty and patient characteristics. Since frailty has been found to be associated with higher mortality, independent of clinical characteristics and comorbidity, interventions to improve frailty have the potential to contribute to better quality of life and lower mortality among dialysis patients. In addition, greater attention should be focused on the possibility that early rehabilitation of dialysis patients might improve poor outcomes. Clinical research should aim to devise an adequate strategy to address frailty, including identifying the optimal timing for intervention.
\end{abstract}

Keywords: Frailty, Chronic kidney disease, Dialysis, Mortality, Intervention

\section{Background}

Because Japan has the world's highest life expectancy and a persistently low birth rate, Japan's population is aging more rapidly than any other country [1]. A systematic review and meta-analysis [2] identified five studies incorporating 11,940 Japanese people aged 65 years or older living in the community and demonstrated that the pooled prevalences of frailty, prefrailty, and robustness based on the Fried criteria were 7.4, 48.1, and 44.4\%, respectively. Stratified analyses showed that women were frailer than men and that prevalence of frailty increased with age.

The age of the dialysis patient population in Japan is also increasing yearly. The number of prevalent dialysis patients in Japan was 320,448 in 2014 [3], and the mean age of prevalent dialysis patients was 67.5 years and are likely the older dialysis populations of most other countries in the world. Since $65 \%$ of Japanese dialysis patients in 2014 are 65 years of age or more, and 32\% are 75 years of age or above (Fig. 1), it is becoming important for dialysis staff members to understand frailty, which is common in elderly dialysis populations.

\footnotetext{
* Correspondence: knitta@twmu.ac.jp

'Department of Medicine, Kidney Center, Tokyo Women's Medical University,

8-1 Kawada-cho, Shinjuku-ku, Tokyo 162-8666, Japan

Full list of author information is available at the end of the article
}

Frailty has been described as a loss of functional, cognitive, and physiologic reserves that leads to a vulnerable condition [4]. Frailty is a state of increased vulnerability to poor recovery of homeostasis following a stress, and it increases the risk of adverse outcomes, including falls, delirium, and disability [5]. An important perspective for therapeutic approach to frailty is to consider how the complex mechanism of aging promotes the cumulative decline of multiple physiological systems, consequent disturbance of homeostatic reserves, and vulnerability to disproportionate changes in health status in response to relatively minor stressor events.

Chronic kidney disease (CKD) accelerates the aging process via protein energy wasting, uremic toxins, inflammation, and oxidative stresses [6]. These combined effects of chronological and pathological aging may explain why the frailty phenotype is much more common in the CKD population irrespective of dialysis therapy. This article reviews focus on the recent frailty consensus in older adults and how to apply it to the dialysis population.

\section{Definition of frailty}

Operational definitions of frailty have incorporated the concepts of multiple contributing causes and multiple manifestations in the form of a syndrome. Fried et al. [4] 


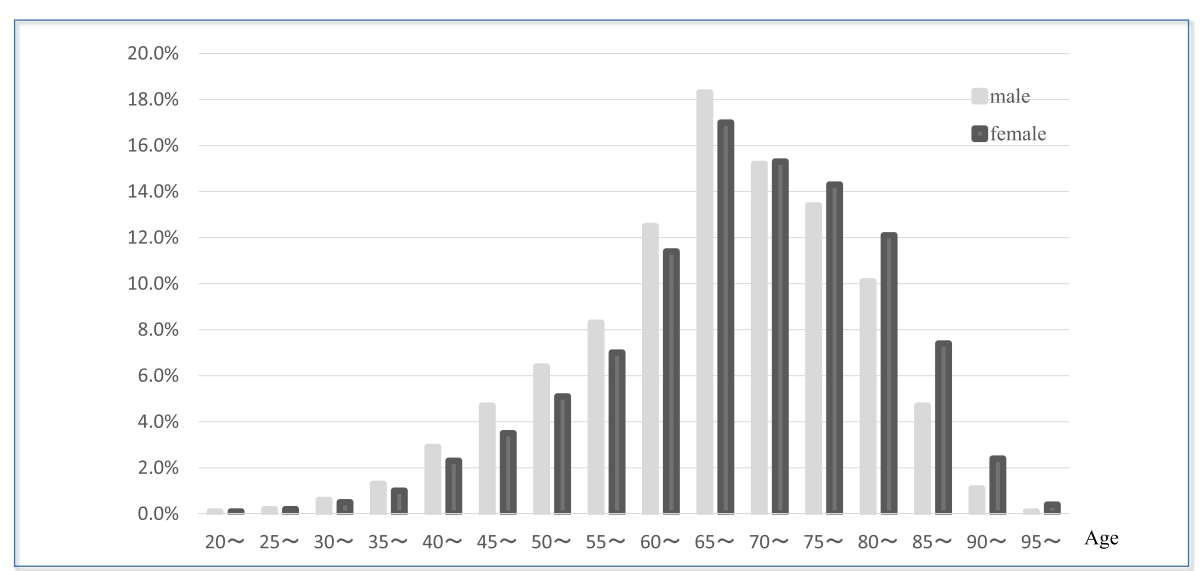

Fig. 1 Distribution of dialysis patients according to age in the Annual Report of the Japanese Society for Dialysis Therapy as of 31 December 2014

have defined a frailty phenotype consisting of at least three of the following unintentional weight loss, exhaustion, physical inactivity, slow gait speed, and weak grip strength. According to this definition, approximately $7 \%$ of community-dwelling elderly in a large US cohort study were frail, and frailty was significantly associated with female sex, older age, and higher comorbidity burden. In order to apply the concept of frailty to patients with CKD or end-stage renal disease (ESRD), the frailty phenotype has been adapted in numerous ways, the most common of which is to substitute patients' selfreport of physical functioning for direct measures of physical performance $[7,8]$.

Two approaches to define physical frailty have become popular. The first deficit model consists of adding together an individual's number of impairments and conditions to create a frailty index [9]. The second model was originally defined as a specific physical phenotype consisting of a constellation of five possible components: weight loss, exhaustion, weakness, slowness, and reduced physical activity, which marked an underlying physiologic state of multisystem and energy dysregulation [10]. Both of these definitions are currently used to define a frail state and a prefrail state, a condition between the frail state and nonfrail state. Many other definitions of frailty have been proposed, but the heterogeneity of definitions may have contributed to the inability to agree on a single operational definition of frailty that satisfies all experts.

A recent consensus conference of European and American frailty experts defined frailty as a medical syndrome with multiple causes and contributors that is characterized by diminished strength, endurance, and reduced physiologic function that increases an individual's vulnerability to developing increased dependency and/or to death [11]. The consensus conference showed four recommendations: (1) physical frailty is an important medical syndrome, (2) simple screening tests are available to be used by physicians to recognize frail persons and identify persons with physical frailty or at risk of frailty, (3) physical frailty is a manageable condition, and (4) all persons older than 70 years should be screened for frailty. Since aging and chronic diseases likely contribute to the development of frailty through mechanisms that include oxidative stress, inflammation, and reductions in serum anabolic hormone levels [10], it is not surprising that $\mathrm{CKD}$, which itself can lead to all of the above, is associated with a higher prevalence of frailty in community-dwelling elderly [12]. However, the definition or the diagnostic criteria of 'frailty' have not gained the broad consensus.

\section{Prevalence of frailty in the predialysis and dialysis population}

CKD represents a formidable cause of biochemical changes and is also a physiological stressor, causing premature occurrence of age-related changes. The combined effect of aging and CKD may represent a higher dose of physiological changes that lead to unsuccessful aging [12]. An association between frailty and predialysis CKD has recently recognized. A systematic review of frailty in CKD found that multiple studies have demonstrated a strong and consistent relationship between worsening kidney function and poor performance on physical function tests [13]. In a large study of predialysis CKD patients enrolled in the third $\mathrm{Na}$ tional Health and Nutrition Evaluation Survey, increasing severity of predialysis CKD patients was strongly associated with occurrence of frailty [14], suggesting that more severe metabolic abnormalities carried by worsening kidney function lead to more significant levels of frailty.

Johansen et al. used a self-report-based definition of frailty to assess the prevalence and significance of frailty 
among the 2275 dialysis patients participating in the Dialysis Morbidity and Mortality Wave 2 study [8]. The results revealed that two thirds of the patients were frail, including those who were under the age of 65 years. A multivariable logistic regression analysis suggested that older age, female sex, and hemodialysis were independently associated with frailty. A Cox proportional hazards model indicated that frailty was independently associated with higher risk of death (adjusted hazard ratio (HR) $2.24,95 \%$ confidence interval (CI) 1.60-3.15) and with a combined outcome of death and hospitalization (adjusted HR 1.63, 95\% CI 1.41-1.87). Since then, the Fried frailty phenotype has been applied to prevalent dialysis populations in the USA $[15,16]$. The prevalence was lower when measured by this method, $30-42 \%$, but was still four to six times that of healthy elderly persons despite inclusion of all adults in these studies rather than only those above 65 years of age. The prevalence of frailty among ESRD patients has varied with the cohorts, probably as a result of differences between the methods used to assess frailty [17]. Differences in patient characteristics, such as dialysis vintage and severity of comorbidities, probably contribute to the variation. Nevertheless, all studies have shown a substantially higher prevalence of frailty among ESRD patients than among community-dwelling elderly.

Because of the high burden of comorbid illness in dialysis patients and the high overall mortality, it is important to consider whether frailty provides prognostic information in this population. If comorbidity and inflammatory exist already in the dialysis population, the presence of frailty may not improve prediction of adverse outcomes. However, frailty has been found to be independently associated with higher mortality in all studies that have examined the association between frailty and mortality to date. Frailty has also been found to be associated with higher risk of falls and fractures [18, 19]. There is an ongoing debate about the value of frailty assessment in dialysis populations and the methods by which frailty should be assessed $[20,21]$, and longitudinal studies are needed to provide the answers.

\section{Screening and management of frailty}

Sufficient evidence exists for the implementation of frailty screening of persons 70 years of age and older by health care providers. Simple rapid screening tests that allow physicians to rapidly identify frail persons have been developed and validated. Examples of some commonly used and validated frailty tools are the FRAIL (Table 1) [22] and the Clinical Frailty Scale (Table 2) [23]. A screening approach is also being carried out widely in Japan, and interventions suggested by the consensus group have been provided successfully [24]. They
Table 1 The simple "FRAIL" questionnaire screening tool

3 or greater $=$ frailty; 1 or $2=$ prefrail

Fatigue: are you fatigued?

Resistance: cannot walk up 1 flight of stairs?

Aerobic: cannot walk 1 block?

Illnesses: do you have more than 5 illnesses?

Loss of weight: have you lost more than $5 \%$ of your weight in the past 6 months?

compared the comprehensive geriatric assessment (CGA) between specified elderly individuals at risk of requiring long-term care insurance and uncertified elderly people, and also compared CGA between the risk group and non-risk group, in subcategories of the "Kihon Checklist," including the physical strength, nutrition/oral function, overall low score on questions 1-20, houseboundness, cognitive function, and depression risk (Fig. 2). They concluded that the assessments of physical strength and cognitive function were more useful as means of identifying frail elderly.

We are aware of a few published studies that were specifically designed to examine frailty in the dialysis population. Unfortunately, the results of recent studies suggest that the functional status in the absence of intervention declines further after initiating dialysis among very elderly patients $[25,26]$, making it imperative to consider treatments or interventions that reverse their downward trajectory. Since physical inactivity is part of the definition of frailty, interventions that increase activity may reverse frailty directly or indirectly if they also improve physical performance or symptoms of fatigue and exhaustion. Some studies have shown that hemodialysis patients are extremely inactive [27-29] and that their low physical activity is associated with poorer physical performance [30] and lower survival rates [31, 32]. Few studies have focused on increasing the habitual physical activity of the dialysis population $[33,34]$, but such a strategy seems promising and should be investigated. Even in the absence of solid evidence for a benefit in the dialysis population, dialysis patients should be encouraged to follow physical activity guidelines for older patients.

There have been numerous studies of more vigorous exercise training programs designed to increase the exercise capacity or physical performance of dialysis patients [35], and although many of the studies have been small and/or of low quality, since the majority have shown improvements and patients with lower baseline functioning have been found to derive greater benefit in one of the largest exercise intervention studies [36], aerobic exercise training would seem to have the potential to improve frailty. However, the vigorous nature of such training programs has led to the exclusion of large numbers of hemodialysis patients as ineligible, and frail patients 
Table 2 The clinical frailty scale (CFS)

\begin{tabular}{ll}
\hline CFS score & Interpretation \\
\hline 1 & Very fit: robust, active, energetic, motivated, and fit; fittest in their age group \\
3 & Well: without active disease but not as fit as those in category 1 \\
4 & Well: with treated comorbid disease \\
5 & Apparently vulnerable: not dependent but has symptoms from comorbid disease (such as being slowed up) \\
6 & Mildly frail: limited dependence on others for instrumental activities of daily living \\
7 & Moderately frail: help is needed for instrumental activities of daily living and activities of daily living \\
8 & Severely frail: completely dependent on others for instrumental activities of daily living and activities of daily living or terminally ill \\
9 & Very severely frail: completely dependent, approaching the end of life. Typically, they could not recover even from a minor illness. \\
& Terminally ill: approaching the end of life. This category applies to people with a life expectancy <6 months, who are not otherwise \\
\hline
\end{tabular}

would be more likely have factors that lead to exclusion. Moreover, there has been a high rate of patient refusal to participate in such programs when offered, suggesting that fear or reluctance to engage in vigorous activity is a barrier to patients' adoption of exercise programs. Thus, the extent to which aerobic exercise training during dialysis or at some other time can reverse frailty remains to be determined.

Because weakness is part of frailty, and muscle atrophy is a key underlying mechanism [37], resistance exercises or other anabolic interventions might be logical choices to ameliorate frailty in the dialysis population [38]. Indeed, resistance training has been shown to increase muscle strength in both hemodialysis patients [38] and institutionalized nonagenarians [39], thereby demonstrating that such programs are possible, even among patients with extremely low functioning, and that they can be beneficial. Thus, referral of frail individuals for physical therapy and strength training should be considered when weakness or frailty is detected.

\section{Interventions for frail older adults}

The development of strategies, such as communitybased interventions, to reduce the risk of disability, including physical frailty, is required worldwide. Physical frailty is bidirectional and potentially reversible. Therefore, interventions have been developed for the condition, and exercise has been shown to exert a positive functional effect on physical frailty [40]. Although interventions, including exercise, nutrition, and education, for older adults at high risk of disability may improve their quality of life, there is little evidence available to show whether interventions reduce the onset of disability with physical frailty [41]. Makizato et al. [42] has recently reported the effects of a community disability prevention program for frail older adults. A total of 514 community-dwelling older adults aged 65 years or older with physical frailty who had undergone baseline assessment and participated in community-based intervention studies (participants) or did not (non-participants) were included in the study. They conclude that participation in community-based

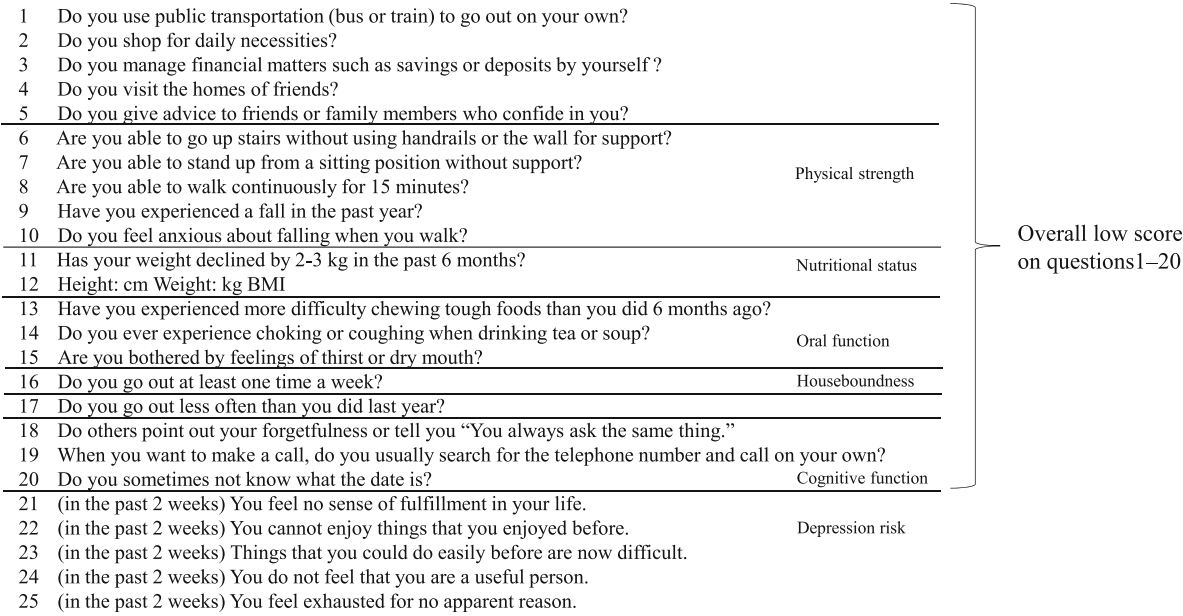

Fig. 2 Kihon Checklist of 25 items and seven categories for screening "specified elderly" individuals for frailty 
intervention studies could reduce the incidence of disability in older adults with physical frailty.

A systematic review has shown that exercise interventions are beneficial and feasible and can be implemented safely in the ESRD population [43]. Both aerobic and resistance exercise interventions, administered in the dialysis facility or outside of dialysis, have resulted in improvements in physical function [44]. However, there are several limitations of the methodologic issues with studies of exercise in dialysis patients, including uncertainty about the optimal modality and dose of exercise, the best time for intervention, safety and health concerns, and frequent hospitalizations and clinical status changes in the dialysis population that can interrupt training. Conclusions were limited by the heterogeneity of the ESRD population, the presence of multiple comorbid conditions, and difficulty in implementing long-term interventions given the high rate of drop-out in the studies to date and the high mortality in the patient population.

\section{Conclusion}

Frailty is common in the older dialysis population and is associated with adverse outcomes, including death, hospitalization, falls, and fractures. Studies are required to determine whether interventions can improve frailty. The potential association between frailty of predialysis patients and higher risk of ESRD would suggest that early intervention may be effective, but it is also important to consider the dialysis population whose current functioning is extremely impaired.

\section{Acknowledgements}

The authors would like to thank all dialysis staffs who gave us the chance to write this review.

\section{Funding}

None.

\section{Availability of data and materials}

Not applicable.

\section{Authors' contributions}

KN planned the review, searched the literature, and prepared the article. $\mathrm{NH}$ searched the literature and assisted in writing the article. KT planned the context of this article and assisted in writing the article. All authors read and approved the final manuscript.

Ethics approval and consent to participate

Not applicable.

\section{Consent for publication}

Not applicable.

\section{Competing interests}

The authors declare that they have no competing interests.

\section{Publisher's Note}

Springer Nature remains neutral with regard to jurisdictional claims in published maps and institutional affiliations.

\section{Author details}

'Department of Medicine, Kidney Center, Tokyo Women's Medical University, 8-1 Kawada-cho, Shinjuku-ku, Tokyo 162-8666, Japan. ²Department of Blood Purification, Kidney Center, Tokyo Women's Medical University, Tokyo, Japan.

Received: 10 June 2017 Accepted: 10 July 2017

Published online: 09 October 2017

\section{References}

1. Arai H, Ouchi Y, Toba K, Endo T, Shimokado K, Tsubota K, et al. Japan as the front-runner of super-aged societies: perspectives from medicine and medical care in Japan. Geriatr Gerontol Int. 2015;15:673-87.

2. Kojima G, lliffe S, Taniguchi $Y$, Shimada H, Rakugi H, Walters K. Prevalence of frailty in Japan: a systematic review and meta-analysis. J Epidemiol. 2016.

3. Masakane I, Nakai S, Ogata S, Kimata N, Hanafusa N, Hamano T, et al. Annual dialysis data report 2014, JSDT renal data registry (JRDR). Ren Replace Ther. 2017:3:18.

4. Fried LP, Tangen CM, Walston J, Newman AB, Hirsch C, Gottdiener J, et al. Frailty in older adults: evidence for a phenotype. J Gerontol A Viol Sci Med Sci. 2001;56:M146-56.

5. Walston J, Hadley EC, Ferrucci L, Guralnik JM, Newman AB, Studenski SA, et al. Research agenda for fraity in doler sdults: toward a better understanding of physiology and etiology: summary from the American Geriatrics Society/National Institute on Aging Research Conference on Frailty in Older Adults. J Am Geriatr Soc. 2006;54:991-1001.

6. Nitta K, Hanafusa N, Tsuchiya K. Recent advances in the pathophysiology and management of protein-energy wasting in chronic kidney disease. Ren Replace Ther. 2016;2:4.

7. Woods N, LaCroix A, Gray S, Aragaki A, Cochrane B, Brunner R, et al. Frailty: emergence and consequences in women aged 65 and older in the Women's Health Initiative Observational Study. J Am Geriatr Soc. 2005;53:1321-30.

8. Johansen $\mathrm{KL}$, Chertow GM, Jin C, Kutner NG. Significance of frailty among dialysis patients. J Am Soc Nephrol. 2007;18:2960-7.

9. Rockwood K, Mitnitski A. Frailty defined by deficit accumulation and geriatric medicine defined by frailty. Clin Geriatr Med. 2011;27:17-26.

10. Fried LP, Ferrucci L, Darer J, Williamson JD, Anderson G. Untangling the concepts of disability, frailty, and comorbidity: implications for improved targeting and care. J Gerontol A Biol Sci Med Sci. 2004;59:255-63.

11. Morley JE, Vellas B, van Kan GA, Anker SD, Bauer JM, Bernabei R, et al. Frailty consensus: a call to action. J Am Med Dir Assoc. 2013;14:392-7.

12. Shlipak $M$, Stehman-Breen $C$, Fried $L$, Song $X$, Siscovick $D$, Fried $L$, et al. The presence of frailty in elderly persons with chronic renal insufficiency. Am J Kidney Dis. 2004;43:861-7.

13. Kalantar-Zadeh K, Ikizler TA, Block G, Avram MM, Kopple JD. Malnutritioninflammation complex syndrome in dialysis patients: causes and consequences. Am J Kidney Dis. 2003;42:864-81.

14. Wilhelm-Leen ER, Hall YN, Tamura MK, Chertow GM. Frailty and chronic kidney disease: the Third National Health and Nutrition Evaluation Survey. Am J Med. 2009;122:664-71.

15. McAdams-Demarco MA, Law A, Salter ML, Boyarsky B, Gimenez L, Jaar BG, et al. Frailty as a novel predictor of mortality and hospitalization in individuals of all ages undergoing hemodialysis. J Am Geriatr Soc. 2013;61:896-901.

16. Johansen KL, Dalrymple LS, Delgado C, Kaysen GA, Kornak J, Grimes B, et al. Association between body composition and frailty among prevalent hemodialysis patients: a USRDS special study. J Am Soc Nephrol. 2014:25:381-9.

17. Johansen $\mathrm{KL}$. The frail dialysis population: a growing burden for the dialysis community. Blood Purif. 2015;40:288-92.

18. McAdams-DeMarco MA, Suresh S, Law A, Salter ML, Gimenez LF, Jaar BG, et al. Frailty and falls among adult patients undergoing chronic hemodialysis: a prospective cohort study. BMC Nephrol. 2013;14:224

19. Delgado C, Shieh S, Grimes B, Chertow GM, Dalrymple LS, Kaysen GA, et al. Association of self-reported frailty with falls and fractures among patients new to dialysis. Am J Nephrol. 2015;42:134-40. Epub ahead of print.

20. Painter P, Kuskowski M. A closer look at frailty in ESRD: getting the measure right. Hemodialysis Int. 2013;17:41-9.

21. Johansen KL, Dalrymple LS, Delgado C, Kaysen GA, Kornak J, Grimes B, et al. Comparison of self-report-based and physical performance-based frailty definitions among patients receiving maintenance hemodialysis. Am J Kidney Dis. 2014;64:600-7. 
22. Morley JE, Malmstrom TK, Miller DK. A simple frailty questionnaire (FRAIL) predicts outcomes in middle aged African Americans. J Nutr Health Aging. 2012;16:601-8.

23. Rockwood K, Song X, MacKnight C, Bergman H, Hogan DB, McDowell I, et al. A global clinical measure of fitness and frailty in elderly people. CMAJ. 2005;173:489-95.

24. Fukutomi E, Okumiya K, Wada T, Sakamoto R, Ishimoto Y, Kimura Y, et al. Importance of cognitive assessment as part of the "Kihon Checklist" developed by the Japanese Ministry of Health, Labor and Welfare for prediction of frailty at a 2-year follow up. Geriatr Gerontol Int. 2013;13:654-62.

25. Kurella Tamura M, Covinsky KE, Chertow GM, Yaffe K, Landefeld CS, McCulloch CE. Functional status of elderly adults before and after initiation of dialysis. N Engl J Med. 2009;361:1539-47.

26. Jassal SV, Chiu E, Hladunewich M. Loss of independence in patients starting dialysis at 80 years of age or older. N Engl J Med. 2009;361:1612-3.

27. Johansen KL, Chertow GM, Kutner NG, Dalrymple LS, Grimes BA, Kaysen GA. Low level of self-reported physical activity in ambulatory patients new to dialysis. Kidney Int. 2010;78:1164-70.

28. Avesani C, Trolonge S, Deleaval P, Baria F, Mafra D, Faxen-Irving G, et al. Physical activity and energy expenditure in haemodialysis patients: an international study. Nephrol Dial Transplant. 2012;27:2430-4.

29. Matsuzawa R, Matsunaga A, Wang G, Kutsuna T, Ishii A, Abe $Y$, et al. Habitual physical activity measured by accelerometer and survival in maintenance hemodialysis patients. Clin J Am Soc Nephrol. 2012;7:2010-6.

30. Johansen KL, Painter P, Kent-Braun JA, Ng AV, Carey S, Da Silva M, et al. Validation of questionnaires to estimate physical activity and functioning in end-stage renal disease. Kidney Int. 2001;59:1121-7.

31. O'Hare AM, Tawney K, Bacchetti P, Johansen KL. Decreased survival among sedentary patients undergoing dialysis: results from the dialysis morbidity and mortality study wave 2. Am J Kidney Dis. 2003;41:447-54.

32. Johansen KL, Kaysen GA, Dalrymple LS, Grimes BA, Glidden DV, Anand S, et al. Association of physical activity with survival among ambulatory patients on dialysis: the comprehensive dialysis study. Clin J Am Soc Nephrol. 2013;8: 248-53

33. Bulckaen M, Capitanini A, Lange S, Caciula A, Giuntoli F, Cupisti A. Implementation of exercise training programs in a hemodialysis unit: effects on physical performance. J Nephrol. 2011;24:790-7.

34. Nowicki M, Murlikiewicz K, Jagodzińska M. Pedometers as a means to increase spontaneous physical activity in chronic hemodialysis patients. J Nephrol. 2010;23:297-305.

35. Johansen $\mathrm{KL}$. Exercise in the end-stage renal disease population. J Am Soc Nephrol. 2007;18:1845-54.

36. Painter P, Carlson L, Carey S, Paul SM, Myll J. Low-functioning hemodialysis patients improve with exercise training. Am J Kidney Dis. 2000;36:600-8.

37. Delgado C, Doyle JW, Johansen KL. Association of frailty with body composition among patients on hemodialysis. J Ren Nutr. 2013;23:356-62.

38. Johansen KL, Painter PL, Sakkas GK, Gordon P, Doyle J, Shubert T. Effects of resistance exercise training and nandrolone decanoate on body composition and muscle function among patients who receive hemodialysis: a randomized, controlled trial. J Am Soc Nephrol. 2006:17:2307-14.

39. Fiatarone MA, Marks EC, Ryan ND, Meredith CN, Lipsitz LA, Evans WJ. High-intensity strength training in nonagenarians. Effects on skeletal muscle. JAMA. 1990;263:3029-34.

40. Theou O, Stathokostas L, Roland KP, Jakobi JM, Patterson C, Vandervoort AA, et al. The effectiveness of exercise interventions for the management of frailty: a systematic review. J Aging Res. 2011;2011:569194.

41. Michel JP, Cruz-Jentoft AJ, Cederholm T. Frailty, exercise and nutrition. Clin Geriatr Med. 2015;31:375-87.

42. Makizato $H$, Shimada $H$, Doi T, Tsutumimoto $K$, Yoshida D, Suzuki T. Effects of a community disability prevention program for frail older adults at 48month follow up. Geriatr Gerontol Int 2017. in press

43. Barcellos FC, Santos IS, Umpierre D, Bohlke M, Hallal PC. Effects of exercise in the whole spectrum of chronic kidney disease: a systematic review. Clin Kidney J. 2015;8:753-65.

44. Sheshadri A, Johansen KL. Prehabitation for the frail patients approaching ESRD. Semin Nephrol. 2017:37:159-72.

\section{Submit your next manuscript to BioMed Central and we will help you at every step:}

- We accept pre-submission inquiries

- Our selector tool helps you to find the most relevant journal

- We provide round the clock customer support

- Convenient online submission

- Thorough peer review

- Inclusion in PubMed and all major indexing services

- Maximum visibility for your research

Submit your manuscript at www.biomedcentral.com/submit
Biomed Central 